\title{
A central role for free heme in the pathogenesis of severe malaria: the missing link?
}

\author{
Ana Ferreira • József Balla $\cdot$ Viktória Jeney $\cdot$ \\ György Balla $•$ Miguel P. Soares
}

Received: 21 February 2008 /Revised: 10 April 2008 / Accepted: 9 May 2008 /Published online: 19 July 2008

(C) The Author(s) 2008

\begin{abstract}
Malaria, the disease caused by Plasmodium infection, is endemic to poverty in so-called underdeveloped countries. Plasmodium falciparum, the main infectious Plasmodium species in sub-Saharan countries, can trigger the development of severe malaria, including cerebral malaria, a neurological syndrome that claims the lives of more than one million children $(<5$ years old) per year. Attempts to eradicate Plasmodium infection, and in particular its lethal outcomes, have so far been unsuccessful. Using well-established rodent models of malaria infection, we found that survival of a Plasmodium-infected host is strictly dependent on the host's ability to up-regulate the expression of heme oxygenase-1 (HO-1 encoded by the gene Hmox 1). HO-1 is a stress-responsive enzyme that catabolizes free heme into biliverdin, via a reaction that releases $\mathrm{Fe}$ and generates the gas carbon monoxide (CO). Generation of $\mathrm{CO}$ through heme catabolism by HO-1 prevents the onset of cerebral malaria. The protective effect of $\mathrm{CO}$ is mediated via its binding to cell-free hemoglobin $(\mathrm{Hb})$ released from infected red blood cells during the blood stage of Plasmodium infection. Binding of $\mathrm{CO}$ to cell-free $\mathrm{Hb}$ prevents heme release and thus generation of free heme, which we found to play a central role in the pathogenesis of cerebral malaria. We will address hereby how defense mechanisms that prevent the deleterious effects of free heme, including the
\end{abstract}

\footnotetext{
A. Ferreira $\cdot$ M. P. Soares $(\bowtie)$

Instituto Gulbenkian de Ciência,

2780-156 Oeiras, Portugal

e-mail: mpsoares@igc.gulbenkian.pt

J. Balla $\cdot$ V. Jeney $\cdot$ G. Balla

Departments of Medicine and Neonatology,

Medical and Health Science Center, University of Debrecen,

4032 Debrecen, Hungary
}

expression of HO-1, impact on the pathologic outcome of Plasmodium infection and how these may be used therapeutically to suppress its lethal outcomes.

Keywords Plasmodium · Malaria $\cdot$ Heme .

Heme oxygenase- $1 \cdot$ Carbon monoxide $\cdot$ Inflammation

$\begin{array}{ll}\text { Abbreviations } \\ \text { BBB } & \text { blood brain barrier } \\ \text { CO } & \text { carbon monoxide } \\ \text { COHb } & \text { carboxyHb } \\ \text { Hb } & \text { hemoglobin } \\ \text { Hpx } & \text { hemopexin } \\ \text { FtH } & \text { ferritin heavy chain } \\ \text { HO-1 } & \text { heme oxygenase-1 } \\ \text { Hp } & \text { haptoglobin } \\ \text { Fe } & \text { iron } \\ \text { ICAM-1 } & \text { intracellular adhesion molecule-1 } \\ \text { LT } & \text { lymphotoxin } \\ \text { LDL } & \text { low-density lipoprotein } \\ \text { MAPK } & \text { mitogen activated protein kinases } \\ \text { Mø } & \text { monocyte/macrophages } \\ \text { MetHb } & \text { methemoglobin } \\ \text { NO } & \text { nitric oxide } \\ \text { PAMP } & \text { pathogen-associated molecular patterns } \\ \text { PRR } & \text { pattern recognition receptors } \\ \text { PMN } & \text { polymorphonuclear cells } \\ \text { ppm } & \text { parts per million } \\ \text { RBC } & \text { red blood cell } \\ \text { ROS } & \text { reactive oxygen species } \\ \text { RNS } & \text { reactive nitrogen species } \\ \text { TLR } & \text { toll-like receptor family } \\ \text { TNF } & \text { tumor necrosis factor } \\ \text { VCAM-1 } & \text { vascular cell adhesion molecule-1 } \\ & \end{array}$




\section{Severe malaria}

Malaria affects an estimated 300-500 million new individuals every year [1]. The life cycle of Plasmodium, the causative agent of malaria, involves initially a clinically silent "liver stage" (reviewed in $[2,3]$ ) and thereafter a "blood stage" (reviewed in [3, 4]) associated with the appearance of overt clinical signs including prostration, respiratory distress, pulmonary edema, convulsions, circulatory collapse, abnormal bleeding, jaundice (reflective of hepatic failure), hemoglobinuria, severe anemia, and/or impaired consciousness [1] (reviewed in [5, 6]). Severe malaria is defined by the occurrence of one or more of these clinical signs in individuals with no apparent cause of disease other than Plasmodium infection. Cerebral malaria, probably the most lethal form of severe malaria, is defined clinically by the development of coma, occurring at least $1 \mathrm{~h}$ after termination of a seizure or correction of hypoglycemia, in individuals where asexual forms of Plasmodium are detected and in which other causes of encephalopathy have been excluded (reviewed in [5]). Lethal forms of severe malaria, including cerebral malaria, are in most cases associated with impaired consciousness, respiratory distress and severe anemia (reviewed in $[5,7]$ ), accounting for the death of more than one million children $(<5$ years old $)$ per year mainly in sub-Saharan Africa [1].

\section{Pathogenesis of severe malaria}

Epidemiologically, lethality associated with Plasmodium infection is a rare event, i.e., less than $1-2 \%$ of afflicted individuals succumb to infection [1]. This suggests that Plasmodium co-evolved with humans to reach an evolutionary "trade-off" in which its life cycle does not compromise that of its host. The cellular and molecular mechanism(s) insuring host viability are thought to rely almost exclusively on its ability to mount an effective immune response against Plasmodium. Over the years, however, it has become apparent that this immune response can contribute in a critical manner to the pathogenesis of severe malaria. Based on its resemblance to the human disease, Plasmodium infection in mice has been widely used to identify cellular and molecular mechanisms underlying the pathogenesis of severe and/or cerebral malaria [8, 9] (reviewed in [3]). The validity of this approach is supported by the finding that some of the key genes involved in the pathogenesis of severe malaria in mice, e.g., tumor necrosis factor (Tnf), lymphotoxin (Lt), intracellular adhesion molecule-1 (Icam-1), and nitric oxide synthases (Nos), are also involved in the pathogenesis of severe malaria in humans (reviewed in [3]).
Plasmodium infection elicits in its host an innate immune response that is critically involved in the pathogenesis of severe malaria. As for other infectious agents, Plasmodium expresses pathogen-associated molecular patterns (PAMP) that can be recognized by host germline-encoded pattern recognition receptors (PRR; reviewed in [10]). These signal in innate immune cells, such as monocyte/macrophages (Mø), to elicit a potent pro-inflammatory response. Glycosylphosphatidylinositol, a glycolipid expressed at the surface of Plasmodium, is recognized via PRR belonging to the Toll-like receptor (TLR) family, i.e., TLR2/TLR1 or TLR2/ TLR6 complexes and to a lesser extent TLR4 [11]. Hemozoin, a crystal derived from heme and generated by Plasmodium (see "The HO system"), can also be recognized by TLR9 $[12,13]$.

The contribution of these PRR to the pathogenesis of severe malaria is suggested by the following set of observations. Polymorphisms in human TLR4 (Asp299Gly/ Thr399Ile) and TLR9 (T-1486C) are associated with susceptibility to severe malaria in children [14] and with the outcome of Plasmodium infection during pregnancy [15], respectively. There is also a polymorphism (Ser180Leu) in Mal/TIRAP (an adaptor molecule required for TLR2 and TLR4 signaling) associated with susceptibility to severe malaria [16]. The involvement of these PRR in the pathogenesis of severe malaria in rodents remains controversial, with some reports suggesting an active role [13] while others not $[17,18]$.

The contribution of host adaptive immunity to the pathogenesis of severe malaria is well illustrated in rodent models of Plasmodium infection (reviewed in $[3,19])$. Once primed by dendritic cells, presumably in the spleen, $\left(\mathrm{T}_{\mathrm{H}}\right)$ cells foster the co-activation of $\mathrm{CD}^{+}$ $\mathrm{T}$ helper cells. It has been suggested that activated $\mathrm{CD} 8^{+}$ $\mathrm{T}$ cells can target brain microvascular endothelial cells, triggering endothelial cell activation and ultimately granzyme- and perforin-dependent programmed cell death, promoting the onset of cerebral malaria (reviewed in $[3,19])$.

The evolutionary "trade-off" allowing Plasmodium and its host to coexist might require an additional mechanism of host defense that does not necessarily involve the host immune response targeting Plasmodium [20]. We reasoned that such a mechanism might operate in a manner that limits the deleterious effects of red blood cell (RBC) lysis, a phenomenon inherent to Plasmodium infection. Hemolysis is associated with release of an estimated $20 \%$ to $40 \%$ of the initial pool of $\mathrm{RBC}$ hemoglobin $(\mathrm{Hb})$ into the circulation (reviewed in [21]). Cell-free $\mathrm{Hb}$ can release its heme prosthetic groups, which, as discussed in the next section, is a highly deleterious event that can promote the onset of severe malaria (Fig. 1). 


\section{Deleterious effects of free heme}

Erythrocytic forms of Plasmodium are in intimate contact with $\mathrm{Hb}$, degrading approximately $60 \%$ to $80 \%$ of the total $\mathrm{RBC} \mathrm{Hb}$ content to use it as a vital source of amino acids (reviewed in [21]). Hb degradation, however, generates free heme and reactive oxygen species (ROS), the combination of which is highly deleterious to erythrocytic schizonts [22] as well as to the infected host.
At concentrations below $5 \mathrm{mM}$, such as outside RBC, cell-free $\mathrm{Hb}$ tetramers dissociate spontaneously into dimers (reviewed in [23]; Fig. 1). In the presence of ROS or reactive nitrogen species (RNS), cell-free $\mathrm{Hb}$ dimers are readily oxidized into methemoglobin (metHb), releasing its heme prosthetic groups [24-26] (reviewed in [23, 27]; Fig. 1). Free heme can be highly cytotoxic to endothelial cells [24-26], a pathologic event that exposes the prothrombotic sub-endothelial matrix to the coagulation cas-

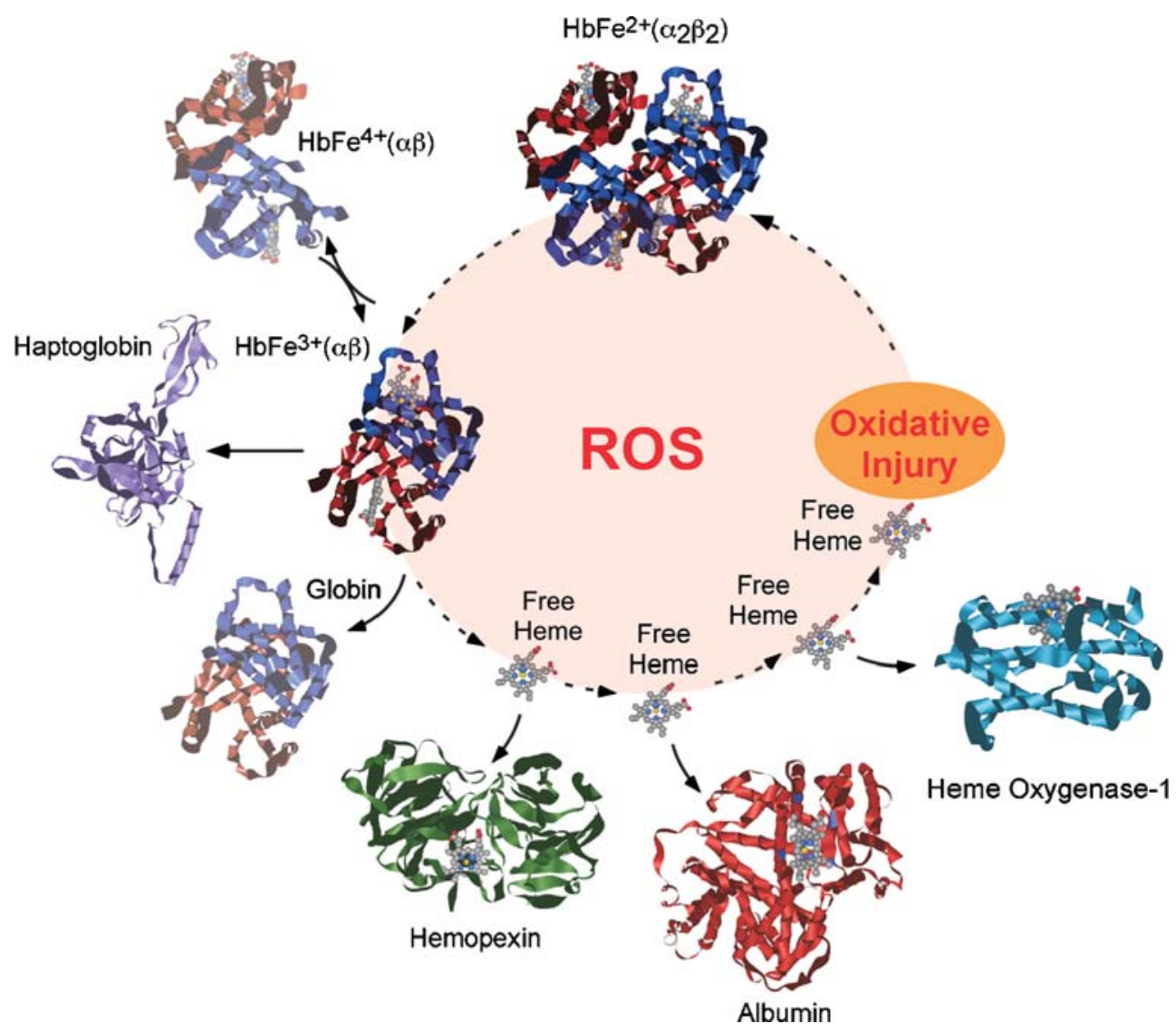

Fig. 1 Defense mechanisms against the free heme generated via $\mathrm{Hb}$ oxidation. When released from infected RBC, ferrous $\mathrm{HbFe}^{2+}\left(\alpha_{2} \beta_{2}\right)$ tetramers disaggregate spontaneously into $\mathrm{Hb}(\alpha \beta)$ dimers. In the presence of ROS (or RNS), cell-free $\mathrm{Hb}(\alpha \beta)$ dimers are readily oxidized into ferric $\mathrm{HbFe}^{3+}(\alpha \beta)$, i.e., metHb. In this process, ferryl $\mathrm{HbFe}^{4+}(\alpha \beta)$, a short-lived intermediate is also generated [93], which can result in a potent pro-inflammatory response (Gabriela Silva, unpublished observations). Under homeostatic conditions, ferric $\mathrm{HbFe}^{3+}(\alpha \beta)$ is scavenged by haptoglobin $(H p)$. The very high affinity of $\mathrm{Hp}$ towards $\mathrm{Hb}\left(>10^{10} \mathrm{~mol}^{-1}\right.$ in humans) is sustained by two Hp-binding sites in the $\mathrm{Hb} \beta$ chain, i.e., $\beta^{11-25}$ and $\beta^{131-146}$ and one in the $\alpha$ chain, i.e., $\alpha^{121-127}$ [94]. Binding of $\mathrm{Hp}$ to $\mathrm{Hb}$ also stabilizes heme, inhibiting its release [95]. During Plasmodium infection, plasma $\mathrm{Hp}$ is depleted, allowing ferric $\mathrm{HbFe}^{3+}(\alpha \beta)$ to release heme. Plasma free heme can be scavenged by hemopexin (Hpx), a plasma protein folded into two homologous $\beta$-propeller domains joined by a linker and binding a single heme molecule via $\mathrm{His}^{213}$ and $\mathrm{His}^{266}$ with the highest affinity $\left(K_{\mathrm{d}}<10^{-12} \mathrm{M}\right.$ in humans $)$ of any other protein described so far [96]. Additional non-covalent interactions between hydrophobic residues of $\mathrm{Hpx}$ and the porphyrin ring and propionate groups of heme act as electrostatic anchors that contribute to heme binding and to coordinate its $\mathrm{Fe}^{3+}$ as well. Once the scavenging capacity of Hpx is exhausted, plasma free heme can be scavenged by albumin, which has two tyrosine residues, i.e., Tyr ${ }^{138}$ and $\mathrm{Tyr}^{161}$ that provide a D-shaped cavity limited by $\mathrm{p}-\mathrm{p}$ stacking interaction with the porphyrin ring of heme with an affinity that is however, $10^{4}$ times lower to that of $\operatorname{Hpx}\left(K_{\mathrm{d}}=10^{-8} \mathrm{M}\right.$ in humans) [97]. In addition, this $3 \mathrm{D}$ structure supplies a donor oxygen (from $\mathrm{Tyr}^{161}$ ) to the $\mathrm{Fe}$ atom of heme, maintaining it in its reduced state, i.e., $\mathrm{Fe}^{2+}$. The interaction of heme with human albumin is further stabilized by two salt bridges, provided by the albumin $\operatorname{Arg}^{114}$ and $\mathrm{Lys}^{190}$ residues (reviewed in [98]). When the scavenging capacity of Hp, Hpx and albumin are exhausted, there is yet an ultimate defense mechanism to avoid free heme accumulation in plasma, i.e., heme catabolism by HO-1. If this is still not sufficient to clear all the free heme generated from $\mathrm{Hb}$ oxidation, a pathologic positive-forward feedback loop is formed in which free heme promotes the generation of ROS that sustain the oxidation of cell-free $\mathrm{Hb}$, with further generation and accumulation of free heme in plasma, ultimately leading to irreversible oxidative injury 
cade, leading to formation of more or less extensive microvascular thrombi with concomitant vaso-occlusion and tissue ischemia.

The underlying cause of free heme cytotoxicity involves most probably its highly hydrophobic nature, which allows the Fe contained within its protoporphyrin IX ring to enter and cross cell membranes as well as other lipid structures [25]. The Fe contained within the protoporphyrin IX ring can act as a potent pro-oxidant, donating electrons that foster the generation of ROS and/or RNS via the Fenton chemistry. This can also occur when Fe is released from the protoporphyrin IX ring of heme, either through nonenzymatic oxidative degradation or enzymatic cleavage, catalyzed by heme oxygenases (HO) [28] (see "Expression of HO-1 modulates the onset of severe malaria"). There is also the possibility that as for other hydrophobic molecules [29], endothelial cells might express "heme receptors" that could mediate its cytotoxic effects [30].

Additional mechanisms via which free heme can be deleterious to endothelial cells include its ability to promote oxidative modification of low-density lipoproteins (LDL) $[24,25]$. Heme-assisted LDL oxidation, involving spontaneous insertion of heme into LDL particles coupled with oxidative interactions between LDL and heme, can lead to oxidative modifications in LDL that are highly cytotoxic to endothelial cells [24].

Free heme can act as a polymorphonuclear (PMN) cell chemoatractant [31], sustaining PMN cell activation [32] and survival [33], thus fostering the generation of ROS that can synergize with free heme to promote further endothelial cell cytotoxicity. As activation of PMN leukocytes by free heme is blocked by pertussis toxin, these cells might recognize free heme specifically via G-protein-coupled receptors [31].

In addition to targeting endothelial cells, free heme can also exert deleterious effects in other cell types. We have recently found that free heme sensitizes non-hematopoietic cells to undergo TNF-mediated programmed cell death (Seixas et al., manuscript submitted for publication). Probably explaining the critical involvement of TNF to the onset of severe malaria [34].

\section{Defense mechanisms against the deleterious effects of free heme}

Plasmodium evolved a series of defense mechanisms against the deleterious effects of free heme, such as its polymerization into hemozoin, an inert crystal in which the $\mathrm{Fe}$ atoms in the protoporphyrin IX ring of heme can no longer act as pro-oxidant catalysts (reviewed in [21]). The importance of this defense mechanism is revealed by the potent therapeutic effects of anti-malarial drugs that inhibit hemozoin formation [35]. While this strategy, i.e., hemozoin formation, allows erythrocytic forms of Plasmodium to replicate efficiently within the confined space of a RBC, it does generate a major caveat, namely that Plasmodium replication will unavoidably lead to hemolysis and $\mathrm{Hb}$ release into the circulation (reviewed in [21]).

Given the highly deleterious effects of free heme to the infected host, there might be a reason why accumulation of cell-free $\mathrm{Hb}$ has been maintained throughout evolution. One possible explanation is that cell-free $\mathrm{Hb}$ can act as a host innate defense mechanism [36]. This notion is supported by the recent observation that cell-free $\mathrm{Hb}$ can recognize molecular patterns expressed specifically by microbial organisms, an effect that when coupled to heme-assisted ROS production, can lead to the clearance of blood-borne microbial pathogens [36]. Whether this innate defense mechanism can target Plasmodium remains to be tested experimentally.

Despite its putative beneficial effects, several defense mechanisms have evolved to cope with the cytotoxicity of cell-free $\mathrm{Hb}$. Under homeostatic conditions, cell-free $\mathrm{Hb}$ can be readily scavenged by haptoglobin ( $\mathrm{Hp})$, a tetrameric $\left(\alpha_{2} \beta_{2}\right)$ plasma protein (human; P00738). Hb/Hp complexes are recognized and internalized via the $\mathrm{Hp}$ receptor (CD163) expressed by monocyte/macrophages (Mø) in the red pulp of the spleen [37]. This allows for heme degradation via the HO system ("Defense mechanisms against the deleterious effects of free heme"; Figs. 2 and 3). Contrary to the $\beta$ chain of $\mathrm{Hp}(\beta, \sim 40 \mathrm{kDa})$ its $\alpha$ chain has two allelic variants, i.e., $H p 1\left(\alpha_{1}, \sim 8.86 \mathrm{kDa}\right)$ and $H p 2\left(\alpha_{2}\right.$, $\sim 17.3 \mathrm{kDa}$ ) that give rise to three possible Hp phenotypes, i.e., Hp1.1, Hp1.2, and Hp2.2 [38]. These have graded affinities for cell-free $\mathrm{Hb}$, i.e., $H p 1.1>H p 1.2>H p 2.2$, as well as for CD163, i.e., Hp2.2>Hp1.2>Hp1.1 [37]. Individuals expressing the $H p 2.2$ phenotype are less likely to develop severe malaria [39], suggesting the existence of a stringent process of natural selection targeting this $\mathrm{Hp}$ allele in endemic areas of Plasmodium infection.

Under hemolytic conditions, such as during Plasmodium infection, circulating $\mathrm{Hp}$ can be depleted, leading to accumulation of cell-free $\mathrm{Hb}$ in plasma. In keeping with this notion, $20-40 \%$ of children infected by Plasmodium falciparum in sub-Saharan countries present undetectable levels of plasma Hp [40]. Presumably, for this reason, cellfree metHb does accumulate in the plasma of individuals suffering from severe malaria [41, 42], which should lead to the prompt release of its heme prosthetic groups (Fig. 1). When this occurs, there are additional mechanisms that can prevent the accumulation of free heme in plasma. One of these relies on hemopexin (Hpx), a monomeric plasma protein ( $\sim 63 \mathrm{kDa}$; human; P02790; Figs. 1 and 2). Under homeostasis, Hpx can scavenge most of the free heme that accumulates in plasma, forming $\mathrm{Hpx} /$ heme complexes. 
Fig. 2 Defense mechanisms against free heme are coupled to heme degradation by $\mathrm{HO}-1$. When cell-free ferric $\mathrm{HbFe}^{3+}$ $(\alpha \beta)$, i.e., metHb, accumulates in plasma, it can be scavenged by circulating haptoglobin $(\mathrm{Hp})$ to be delivered to the Hp receptor (CD163) expressed by Mø in the red pulp of the spleen. This allows for sheltering of the heme prosthetic groups of $\mathrm{HbFe}^{3+}$ $(\alpha \beta)$ as well as for catabolism of the heme groups by HO-1, constitutively expressed by CD163 Mø. If released from ferric $\mathrm{HbFe}^{3+}(\alpha \beta)$, free heme can be scavenged by very high affinity binding to hemopexin (Hpx) and delivered to liver hepatocytes and Mø expressing the Hpx receptor (CD91). Expression of $\mathrm{HO}-1$ in liver hepatocytes and Mø ensures heme catabolism. During the onset of severe malaria, the pool of plasma Hp and Hpx is exhausted, and free heme accumulates in plasma. Free heme can cross cell membranes, e.g., in endothelial cells, where it synergizes with oxidants to induce the expression of HO-1 by which it is catabolyzed. Pathology will only develop when all these defense systems are overwhelmed

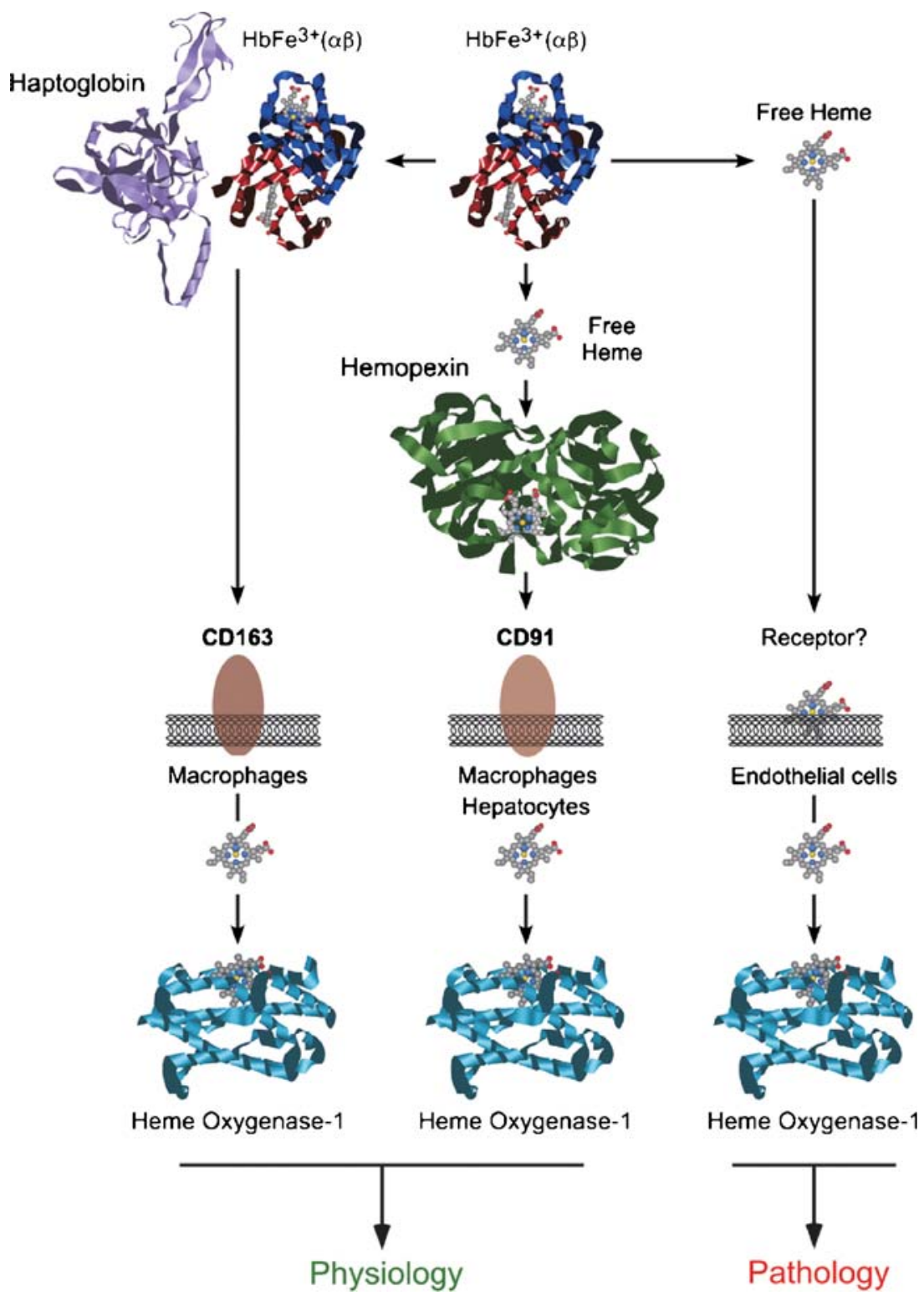

These are recognized by the Hpx receptor (CD91) expressed in hepatocytes, Mø, fibroblasts, adipocytes, neurons, and trophoblasts [43] (Fig. 2). Internalization of these complexes via CD91-assisted endocytosis allows for heme degradation via the HO system [43] (Figs. 2 and 3). Once the scavenging capacity of plasma Hpx is exhausted, free heme can still be scavenged by plasma albumin ( $\sim 66$ kDa; human; P02768; Fig. 1). Whether heme/albumin complexes are recognized by specific receptors allowing for heme degradation via the $\mathrm{HO}$ system has not been established.

We have recently described that the onset of severe malaria in mice is associated with the accumulation of high concentrations of free heme in plasma [8], suggesting that the capacity of plasma $\mathrm{Hp}, \mathrm{Hpx}$, and albumin to prevent free heme accumulation is exhausted during the onset of severe malaria (reviewed in [23, 27]). However, there is yet an ultimate defense mechanism to avoid the deleterious effects of free heme, namely its catabolism by the cellular HO system (Fig. 3).

\section{The HO system}

Heme oxygenases (EC1.14.99.3) are encoded by three distinct genes, i.e., HMOX1 (human; P09601), HMOX2 (human; P30519), and Hmox3 (rat; 070453). HMOX1 and $H M O X 2$ encode two distinct proteins, i.e., HO-1 (32 kDa) and HO-2 (37 kDa), respectively, while Hmox3 is most probably a pseudogene. Under oxidative stress, HO-1 
Fig. 3 The heme oxygenase system. HO-1 catabolizes free heme into biliverdin. Initially, free heme intercalates in the heme-binding pocket of apo HO-1, which cleaves the protoporphyrin IX ring using one $\mathrm{O}_{2}$ molecule and electrons donated by NAD(P)H/CytP450 reductase via a reaction releasing $\mathrm{Fe}^{2+}$ (yellow circle) from its inner core and generating carbon monoxide (CO; gray and red circle). Biliverdin, the protoporphyrin structure released from the heme pocket of HO-1, can be converted into bilirubin by biliverdin reductase $(B V R)$, which uses $\mathrm{NAD}(\mathrm{P}) \mathrm{H}$ as electron donors. All three end products of this reaction, i.e., Fe, $\mathrm{CO}$, and bilirubin, can dampen the deleterious effects of inflammatory reactions
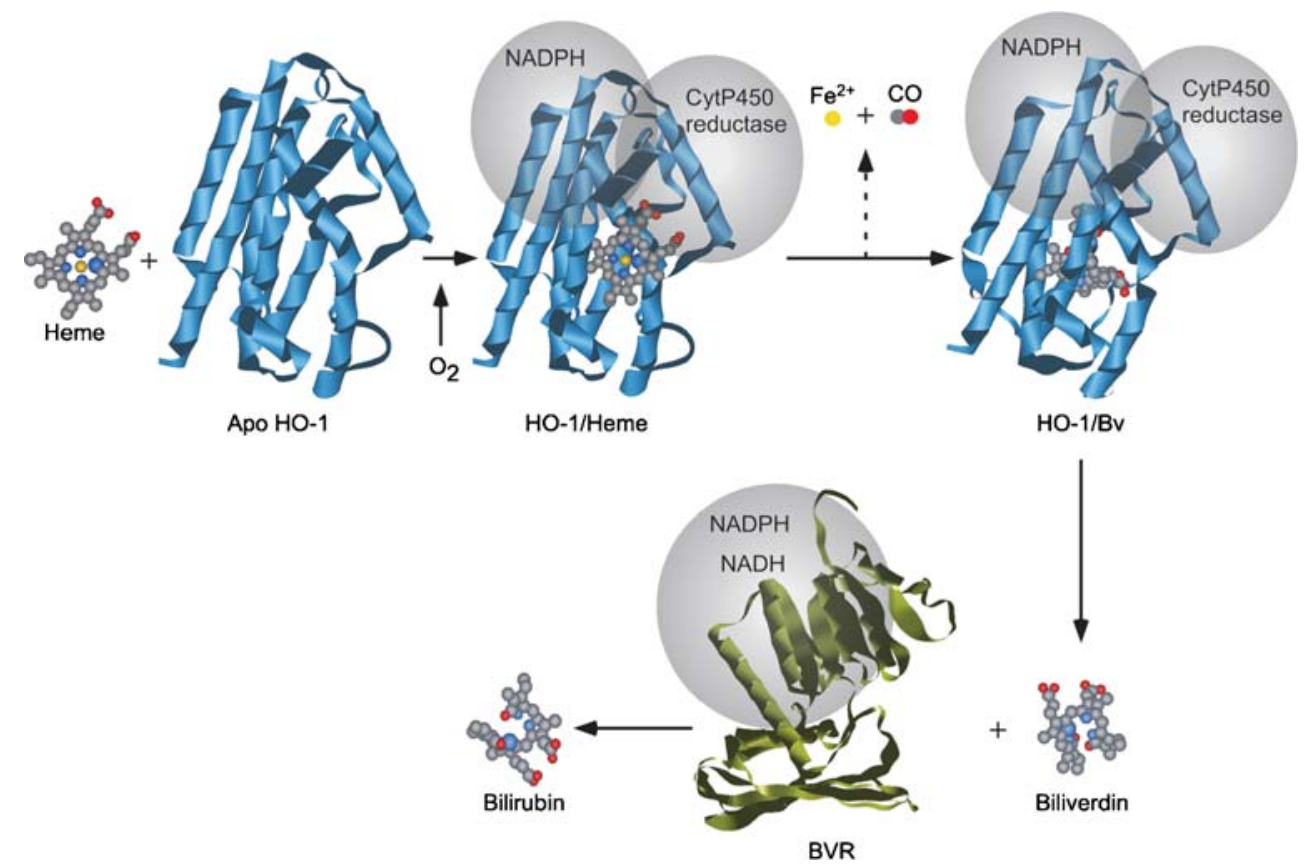

expression is induced ubiquitously, while the expression of HO-2 remains unchanged [8]. Both $\mathrm{HO}$ isoforms can cut the protoporphyrin IX ring of free heme, releasing Fe from its inner core and generating carbon monoxide (CO; Fig. 3). The remaining protoporphyrin structure gives rise to biliverdin, which can be converted by biliverdin reductase into bilirubin, a potent antioxidant [44] (Fig. 3). Biliverdin reductase can also trigger signal transduction and probably mediate in this manner some of the biologic effects attributed to biliverdin (reviewed in [45]).

Heme catabolism by the HO system rids cells of a membrane-permeant $\mathrm{Fe}$, i.e., heme. However, the $\mathrm{Fe}$ released via heme catabolism represents a potential hazard, unless sequestered by ferritin [46], which acts as a vital antioxidant in various experimental models [46-48]. Ferritin is a multimeric (24-subunit) protein ( $\mathrm{H}$ chain, $21 \mathrm{kDa}, \mathrm{L}$ chain, $20.7 \mathrm{kDa})$ with high Fe storing capacity $(4,500 \mathrm{~mol}$ of $\mathrm{Fe}$ per mole of ferritin). The proportion of $\mathrm{H}$ and $\mathrm{L}$ subunits in the ferritin shell depends on the Fe status of the cell (reviewed in [49]). The protective effects of ferritin are attributable in large measure to the ferroxidase activity of the $\mathrm{H}$ chain subunit [50], which catalyzes the oxidation of (ferrous) $\mathrm{Fe}^{2+}$ formed by superoxide or endogenous reductants into (ferric) $\mathrm{Fe}^{3+}$. This process, i.e., Fe nucleation, facilitates $\mathrm{Fe}$ insertion into multimeric ferritin structures, allowing for the functional storage and inactivation of labile (ferrous) $\mathrm{Fe}^{2+}$ that is otherwise capable of fueling the production of toxic hydroxyl radicals $(\mathrm{OH})$ via the Fenton chemistry.

It is now well established that induction of HO-1 expression plays a pivotal role in the resolution of

inflammatory conditions (reviewed in [51]). Malaria seems to provide yet another situation where the potent protective effects of HO-1 are exerted [8].

\section{Expression of HO-1 modulates the onset of severe malaria}

Plasmodium infection, in both mice and humans, is associated with the induction of high levels of HO-1 expression that is neither restricted to a specific cell type nor to a specific organ $[8,52-54]$. We found that mouse strains that express high levels of HO-1 in response to Plasmodium infection do not succumb to severe and/or cerebral malaria, while those that express low levels of HO-1 do so [8] (Seixas et al., manuscript submitted for publication). Perhaps more importantly, deletion of the Hmoxl locus by homologous recombination is sufficient per se to promote the onset of severe and/or cerebral malaria [8] (Seixas et al., manuscript submitted for publication). These observations reveal that induction of HO-1 expression is part of a protective mechanism that suppresses the onset of severe and/or cerebral malaria in mice.

Contrary to HO-1, the expression of HO-2 is not induced in response to Plasmodium infection in mice [8], which would suggest that HO-2 is not critically involved in modulating the pathogenesis of severe and/or cerebral malaria. However, as the outcome of Plasmodium infection in Hmox2-deficient mice has not been reported, we cannot at this point exclude the possibility that HO-2 might 
modulate the pathogenesis of severe and/or cerebral malaria.

Probably critical to our understanding of the mechanism of action of HO-1 is the observation that its protective effects do not correlate with modulation of "parasite burden", i.e., percentage of infected RBC [8]. This suggests that HO-1 can prevent the lethal outcome of Plasmodium infection without interfering with the host immune response controlling parasite burden [8], a general host defense mechanism against infection referred to as "tolerance" [20]. Based on the extremely well-conserved nature of this enzymatic system among mice and humans, it is possible that HO-1 expression might also be protective against the onset of severe and/or cerebral malaria in Plasmodiuminfected children.

If one assumes that HO-1 might play a central role in modulating the pathogenesis of severe malaria in humans, then the prediction would be that spontaneous mutations selected through evolution based on their protective effect against severe malaria might act via HO-1. Sickle cell trait, caused by a single point mutation in one of the $\mathrm{Hb} \beta$-globin chain locus, is probably the best-characterized of such mutations. Sickle cell trait can be associated with the occurrence of mild hemolysis and heme release into the circulation. When exposed chronically to low levels of free heme, cells up-regulate the expression of HO-1 [25, 26, 46], probably explaining why individuals carrying this mutation can have high level of HO-1 expression [55]. It is therefore tempting to speculate that up-regulation of HO-1 might contribute to the protective effect of this hematological condition against the onset of severe malaria. It is also possible that a similar protective mechanism, involving HO-1, could contribute to explain how other hemolytic disorders such as $\alpha$ - and $\beta$-thalassemia or glucose 6phosphate dehydrogenase deficiency also afford protection against severe malaria. However, this remains to be tested experimentally.

Spontaneous disruption of the HMOX1 locus in humans is lethal [56], excluding the possibility of establishing a linear functional link between HO-1 expression and the outcome of Plasmodium infection. However, there is a (GT) $\mathrm{n}$ microsatellite polymorphism in the human HMOXI promoter that regulates in a quantitative manner its response to many stimuli (reviewed in [57]). Individuals with fewer (GT)n repeats have a high HO-1 inducibility, while those with higher (GT)n repeats have a lower response (reviewed in [57]). There are now multiple studies demonstrating that individuals responding more strongly, i.e., fewer (GT)n repeats, are also less likely to develop a series of pathologies (reviewed in [57]). However, in the case of Plasmodium infection, this relationship does not seem to be straightforward. In a recent study, children that succumbed to cerebral malaria were shown to carry more frequently the homozygous short (GT)n repeats $(n<28$; high HO-1 inducibility) than those that do not develop this syndrome [58]. As a cautionary note, however, this study was performed in a very limited sample size, and no correlation between the (GT)n polymorphism and HO-1 expression was assessed in the context of Plasmodium infection [58]. Nevertheless, assuming that in Plasmodiuminfected children the homozygous short (GT)n repeats afford high level of HO-1 expression but no protection against the onset of cerebral malaria, this might be explained by the following set of observations in mice. Expression of HO-1 is significantly induced during the hepatic stages of Plasmodium infection [59]. More importantly, when Hmoxl is deleted by homologous recombination, generation of liver merozoites is reduced by $\sim 70-80 \%$ [59]. This would suggest that a viable interaction of Plasmodium with its host is strictly dependent on the induction of HO-1 expression during both liver and blood stages of infection. Namely, HO-1 expression might favor initially the generation of liver merozoites and their progression into the blood, while expression of HO-1 thereafter might prevent the onset of severe malaria. While this interpretation does not take away the critical role of HO-1 in suppressing the pathogenesis of severe malaria, it suggests that Plasmodium interaction with its human host might have evolved in a way that subverts the HO-1 system to promote both Plasmodium and host survival.

\section{CO and expression of heavy chain ferritin (FtH) prevent the onset of severe malaria}

Congruous with previous observations in other experimental models of disease [60-63], we found that $\mathrm{CO}$ can prevent the development of cerebral malaria in mice [8]. Briefly, under experimental conditions in which more then 95\% of Plasmodium-infected mice develop cerebral malaria, $\mathrm{CO}$ inhalation $(250 \mathrm{ppm})$ at different times after infection reduces the incidence of cerebral malaria to less than 5\% [8]. As for HO-1, CO does not modulate parasite burden, suggesting that it affords host tolerance against Plasmodium infection [20]. That is, CO limits disease severity, i.e., death, associated with a given parasite burden.

The finding that $\mathrm{CO}$ can prevent the onset of cerebral malaria in mice could have important implications for the treatment of this disease in humans, as the protective effect of $\mathrm{CO}$ is achieved when applied as late as $4-5$ days postinfection at a dosage as low as $250 \mathrm{ppm}$ [8]. This suggests that $\mathrm{CO}$ might be used therapeutically, after infection, to prevent the onset of cerebral malaria in humans.

We have also tested whether other end products of heme catabolism by HO-1 exert protective effects. Biliverdin, which we have shown to elicit potent protective effects in 
other experimental models of disease [64], failed to prevent the development of cerebral malaria in mice [8]. This suggests that biliverdin/bilirubin is probably not the main effector mechanism via which HO-1 affords protection against severe and/or cerebral malaria. However, as a cautionary note, failure of biliverdin to exert protective effects may be due to its inability to cross the blood brain barrier (BBB).

Finally, we have recently found that expression of FtH in non-hematopoietic cells suppresses the cytotoxic effects of free heme and prevents the lethal outcome of severe malaria in mice (Seixas et al., manuscript submitted for publication). This salutary effect, which requires FtH ferroxidase activity, acts independently of host immunity against Plasmodium, suggesting that in a similar manner to $\mathrm{CO}$, expression of $\mathrm{FtH}$ can limit disease severity and prevent the lethal outcome of severe malaria under a given parasite burden [20].

\section{Are the protective effects of $\mathrm{CO}$ mediated via signal transduction?}

Understanding further the mechanism(s) of action of $\mathrm{CO}$ might improve the possibility of using this gaseous molecule for therapeutic purposes in humans. There are now several studies suggesting that $\mathrm{CO}$ exerts antiinflammatory [61], cytoprotective [65], and anti- proliferative effects [62] that act in a concerted way to prevent the deleterious effects associated with the development of many pathologic conditions, such as hyperoxic lung injury, rejection of transplanted organs, ischemia and reperfusion injury, severe sepsis or arteriosclerosis, among others (reviewed in [51]). These studies also suggested that $\mathrm{CO}$ acts as a signal transduction molecule to down-modulate inflammation and afford cytoprotection as well as to prevent unfettered cell proliferation (reviewed in [51]). These effects should contribute to the ability of $\mathrm{CO}$ to prevent the onset of severe and/or cerebral malaria.

$\mathrm{CO}$ can react with reduced divalent metals and in particular with $\mathrm{Fe}^{2+}$ contained within the heme groups of hemoproteins (reviewed in [66]). The relative affinity of $\mathrm{CO}$ for different heme prosthetic groups is dictated not only by their Fe "redox status" $\left(\mathrm{Fe}^{2+}\right.$ versus $\left.\mathrm{Fe}^{3+}\right)$ but also by the amino acid sequence in the "heme-binding motifs" of these hemoproteins. This was demonstrated originally for $\mathrm{Hb}$ and later for guanylate cyclase, an enzyme that generates the signal transduction molecule cyclic GMP (cGMP) [67] (reviewed for $\mathrm{Hb}$ in [68]). In the case of guanylate cyclase, the amino acid sequence of its heme-binding motifs impose that $\mathrm{CO}$ binds to heme in a manner that is distinct from that of other biologically active gases such as nitric oxide (NO)
[69]. The net result being that the relative ability of CO to induce cGMP production is significantly lower than that of NO [70]. This led to the notion that guanylate cyclase is a physiologic target of $\mathrm{NO}$, but probably not of $\mathrm{CO}$, despite experimental evidence suggesting that $\mathrm{CO}$ can exert biologic effects via cGMP (reviewed in [71]). Whether the guanylate cyclase/cGMP pathway is involved in the protective effect of $\mathrm{CO}$ against severe malaria remains to be established.

$\mathrm{CO}$ can bind a variety of other hemoproteins, including cytochrome $\mathrm{C}$ oxidase, the terminal electron acceptor in the mitochondrial electron transport chain [72]. As for guanylate cyclase, cytochrome $\mathrm{C}$ oxidase is also a physiologic target of NO (reviewed in [73]). Binding of CO to cytochrome C oxidase can trigger a small burst of mitochondria-derived ROS [74-76] that activates several signal transduction pathways. Among these is the p38 family of mitogenactivated protein kinases (MAPK) [74, 75], a common molecular denominator via which the anti-inflammatory [61], cytoprotective [65], and anti-proliferative effects [62] of $\mathrm{CO}$ are exerted in several cell types.

The p38 family of MAPK is composed of four isoforms encoded by different genes, i.e., $P 38 \alpha$ ( $38 \mathrm{kDa}), P 38 \beta$ (39 kDa), $P 38 \gamma(43 \mathrm{kDa})$, and $P 38 \delta(40 \mathrm{kDa}$; reviewed in [77]). These share sequence homologies ranging from $74 \%$ ( $P 38 \alpha$ versus $P 38 \beta)$ to $98 \%$ ( $P 38 \beta$ versus $P 38 \beta 2)$ and a canonical dual phosphorylation site (Thr-Gly-Tyr; reviewed in [77]). The kinase activity of the $\mathrm{p} 38 \alpha$ and $\mathrm{p} 38 \beta$ isoforms can be inhibited by pyridinyl imidazoles, a class of chemical compounds that does not target the $\mathrm{p} 38 \gamma$ or $\mathrm{p} 38 \delta$ isoforms. The observation that pyridinyl imidazoles can abrogate the anti-inflammatory [61], cytoprotective [65], and antiproliferative [62] effects of $\mathrm{CO}$ led to the hypothesis that these effects might act via the p38 $\alpha$ and/or the p38 $\beta$ isoforms. In keeping with this notion, suppression of $\mathrm{p} 38 \beta$ expression impairs the cytoprotective $[65,78,79]$ and antiproliferative [80] effects of $\mathrm{CO}$, suggesting that $\mathrm{CO}$ acts specifically via this p38 MAPK isoform. Moreover, we found that the mechanism via which CO signals via $p 38 \beta$ also involves the specific targeting of the p $38 \alpha$ isoform for degradation by the $26 \mathrm{~S}$ proteasome pathway [78]. Presumably, $\mathrm{CO}$ alters the ratio of $\mathrm{p} 38 \alpha$ versus $\mathrm{p} 38 \beta$ expression, allowing signaling via the cytoprotective $\mathrm{p} 38 \beta$ to predominate over that of cytotoxic p38 $\alpha$ [78]. Whether (1) mitochondria-derived ROS, (2) p38 $\alpha$ degradation, and/or (3) signaling via $p 38 \beta$ contribute to the protective effect of $\mathrm{CO}$ against severe malaria remains to be established.

There are probably many other signal transduction pathways via which the protective effects of $\mathrm{CO}$ can be exerted (reviewed in [71]). Exposure of naïve Mø to $\mathrm{CO}$ in vitro can induce the expression of peroxisome proliferatoractivated receptor-gamma (PPAR $\gamma$ ) [75], a nuclear hormone receptor that down-regulates a subset of pro- 
inflammatory genes associated with Mø activation [81]. Blocking mitochondria-driven ROS and/or deleting the expression of PPAR $\gamma$ abrogates the anti-inflammatory effects of $\mathrm{CO}$, suggesting that this effect acts via upregulation of $\operatorname{PPAR} \gamma$, presumably via mitochondria-driven ROS [75]. Yet, another signal transduction pathway triggered by $\mathrm{CO}$ in Mø involves the transcription factor hypoxia-inducible factor 1 alpha (HIF-1 $\alpha$ ) [76]. Activation and stabilization of HIF $1 \alpha$ by ROS arising from mitochondria induces the transcription of TGF- $\beta$ [76], a potent anti-inflammatory and cytoprotective cytokine that could contribute to the salutary effects of $\mathrm{CO}$ in many inflammatory conditions, including in severe malaria. Again, the contribution of these signal transduction pathways in the control of the pathogenesis of severe malaria is not defined.

In most studies addressing the mechanisms of action of $\mathrm{CO}$, the assumption has been that this gas targets one or several "upstream" signal transduction pathways that modulate the activity of transcription factors regulating gene expression. However, there are instances where $\mathrm{CO}$ can target transcription factors directly. This is the case for the neuronal Per-ARNT-Sim (PAS) domain protein 2 (NPAS2), a transcription factor implicated in the regulation of circadian rhythms [82]. Binding of $\mathrm{CO}$ to the heme prosthetic group of NPAS2 controls NPAS2 heterodimerization with the brain and muscle arnt-like protein-1 (BMAL1), a transcription factor that regulates NPAS2 DNA binding and transcriptional activity [82]. Whether NPAS2 regulates Plasmodium interaction with its human host remains to be established, but is likely to be the case. Cycles of RBC schizont infection (hemolysis, invasion, replication) are highly synchronous [83] and therefore could be controlled by host transcription factors that regulate circadian rhythms, such as NPAS2.

Most, if not all, of the biological functions attributed to $\mathrm{CO}$ are thought to rely on its binding to $\mathrm{Fe}^{2+}$ in the heme prosthetic groups, e.g., guanylate cyclase, cytochrome $\mathrm{C}$ oxidase, $\mathrm{NAD}(\mathrm{P}) \mathrm{H}$ oxidase (reviewed in [71]). The postulate has been that $\mathrm{CO}$ can alter the $3 \mathrm{D}$ structure of these hemoproteins and modulate in this manner their biologic activity, i.e., signal transduction (reviewed in [71]). While this notion has provided a useful framework to explain the protective effects of $\mathrm{CO}$, our recent finding of an alternative mechanism via which $\mathrm{CO}$ can suppress the onset of severe malaria might challenge this view.

\section{Mechanism underlying the protective effects of $\mathrm{CO}$ : inhibition of heme release from $\mathrm{Hb}$}

We found that one of the mechanisms via which $\mathrm{CO}$ prevents the onset of cerebral malaria relies on its ability to bind cell-free $\mathrm{Hb}$ and form carboxyHb (COHb; Fig. 3). When bound to cell-free $\mathrm{Hb}, \mathrm{CO}$ slows down its rate of oxidation and, subsequently, the rate of heme release from $\mathrm{Hb}$ [8] (Fig. 3). The critical involvement of free heme in the pathogenesis of cerebral malaria is supported by the following set of observations: (1) the protective effect of $\mathrm{CO}$ is associated with a profound decrease $(\sim 95 \%)$ in the accumulation of free heme in plasma of Plasmodiuminfected mice and (2) administration of heme precipitates the onset of cerebral malaria, abrogating the protective effect of $\mathrm{CO}$ [8].

There is further evidence that free heme can dictate susceptibility to cerebral malaria in mice. We found that a given Plasmodium strain that triggers cerebral malaria in mice also leads to higher levels of free heme accumulation in plasma, as compared to another related Plasmodium strain that does not trigger cerebral malaria (Fig. 4a). Moreover, administration of free heme is sufficient per se to precipitate the onset of cerebral malaria in mice infected with the Plasmodium strain that does not trigger cerebral malaria naturally (Fig. 4b). In a similar manner, a Plasmodiuminfected mouse strain that does not develop cerebral malaria naturally (is resistant) has lower levels of plasma free heme, as compared to a mouse strain that develops cerebral malaria naturally (is susceptible; Fig. 4c). Again, heme administration is sufficient per se to precipitate the onset of cerebral malaria in the naturally resistant mouse strain (Fig. 4d) [8]. Taken together, these observations suggest that accumulation of free heme in plasma can explain at least to some extent why some Plasmodium strains trigger cerebral malaria while others do not, as well as why some mouse strains are resistant to cerebral malaria while others are susceptible.

While free heme seems to be critically involved in the pathogenesis of cerebral malaria in mice, there is yet no direct evidence linking functionally free heme to the pathogenesis of severe and/or cerebral malaria in humans. There is indirect evidence, however, to suggest that this might be the case. Individuals developing severe malaria have high levels of plasma metHb [41, 42]. As metHb releases free heme, the prediction is that free heme should accumulate in the plasma of these individuals, a hypothesis we are currently testing. Moreover, individuals that succumb to cerebral malaria express high levels of HO-1 in the brain $[52,53]$ and present high levels of plasma $\mathrm{COHb}$, a "biological fingerprint" of $\mathrm{CO}$ production by the $\mathrm{HO}$ system [84]. Taken together, these observations suggest that some of the key components involved in the pathogenesis of severe malaria in mice, i.e., metHb, HO-1 and $\mathrm{CO}$ are also present during the pathogenesis of severe malaria in humans. Whether the heme/HO-1 system should also play a pivotal role in determining the onset of severe malaria in humans remains to be established. 
Fig. 4 Free heme dictates the onset of cerebral malaria in mice. $\mathrm{C} 57 \mathrm{BL} / 6$ or BALB/c mice were inoculated (i.p.) with $P$. berghei ANKA or $P$. berghei NK65-infected RBC $\left(10^{5}\right)$, i.e., infection [8]. a Survival and heme concentration in proteinfree plasma of C57BL/6 mice infected with either $P$. berghei ANKA (black circles) or NK65 (white circles) at days $0(n=7), 4$ ( $n=4$ for $P$. berghei ANKA), 6 ( $n=30$ and $n=16$ for $P$. berghei $A N K A$ and NK65, respectively), $10(n=10)$, and $15(n=10)$ as it relates to day of infection, i.e., day 0 . Results are shown as mean \pm standard deviation. (*unpaired $t$ test between $P$. berghei ANKA and P. berghei NK65-infected mice at day 6 post-infection, $p<0.01)$. b Survival of C57BL/6 mice infected with either P. berghei ANKA or $P$. berghei NK65 receiving vehicle (white circles; $n=10$ ), $60 \mu \mathrm{mol} / \mathrm{kg}$ ( $n=5 ;$ gray circles) or $90 \mu \mathrm{mol} / \mathrm{kg}(n=12 ;$ black circle) of free heme (i.p.; starting at day 6 post-infection and every $12 \mathrm{~h}$ thereafter). c Survival and heme concentration in protein-free plasma of C57BL/6 mice (black circle) or BALB/c mice (white circle) infected with $P$. berghei ANKA at days $0(n=$ 7 and $n=6$ for $P$. berghei ANKA-infected C57BL/6 mice and BALB/c mice, respectively), 4 ( $n=4$ for $P$. berghei $A N K A$-infected C57BL/6 mice), $6(n=30$ and $n=15$, for $P$. berghei ANKAinfected C57BL/6 mice and BALB/c mice, respectively), 10 $(n=10)$ and $15(n=12)$ as it relates to day of infection, i.e., day 0 . Results are shown as mean \pm standard deviation (*unpaired $t$ test between $P$. berghei ANKA-infected C57BL/ 6 and BALB/C mice at day 6 post-infection, $p<0.01)$. d Survival of $P$. berghei ANKAinfected $\mathrm{BALB} / \mathrm{c}$ mice receiving vehicle (white circle; $n=10$ ), $60 \mu \mathrm{mol} / \mathrm{kg}$ ( $n=9 ;$ grey circles), or $90 \mu \mathrm{mol} / \mathrm{kg}(n=6$; black circle) free heme (i.p; starting at day 6 post-infection and every $12 \mathrm{~h}$ thereafter) a
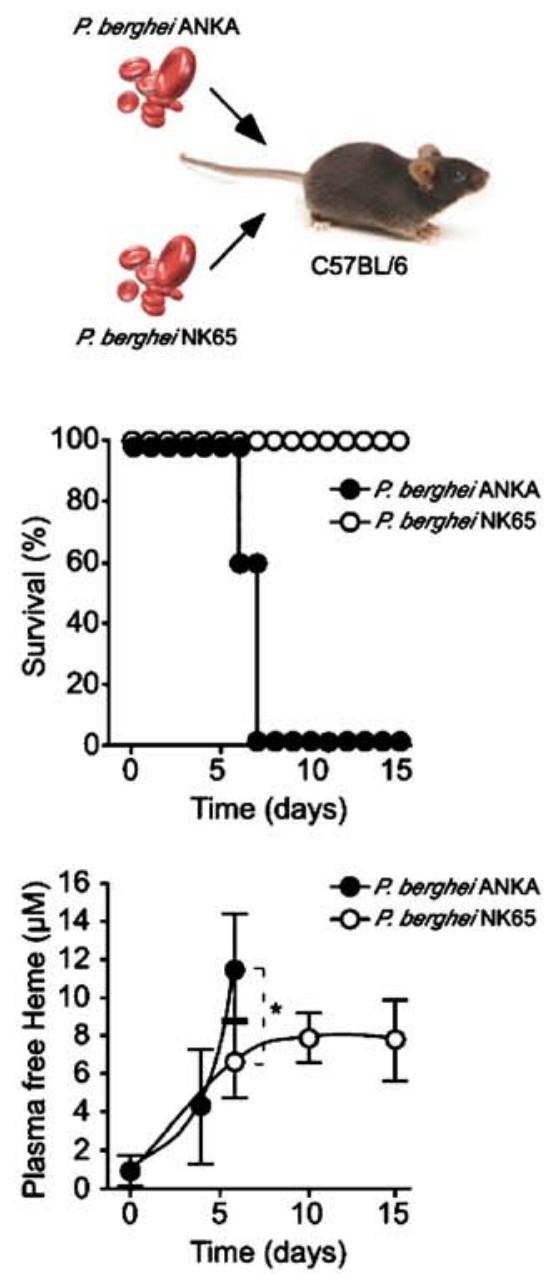

$b$
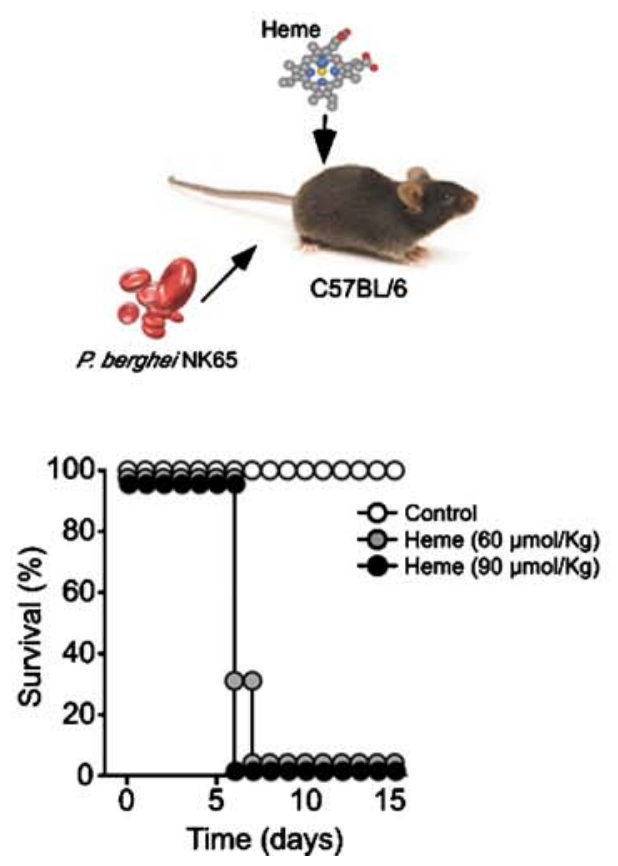

C
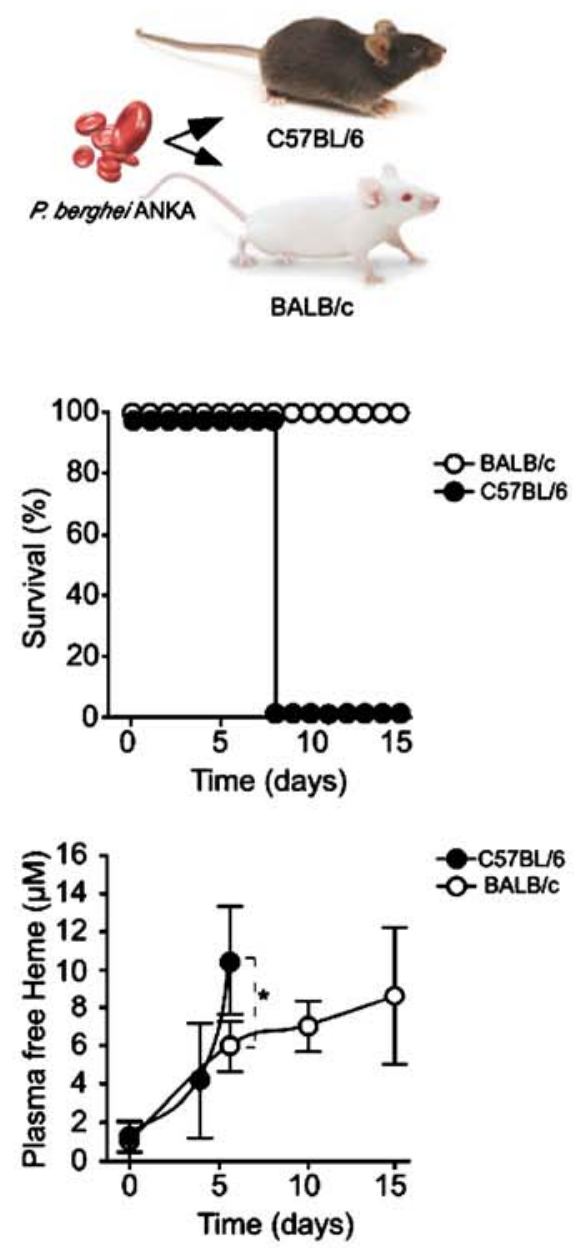

$d$
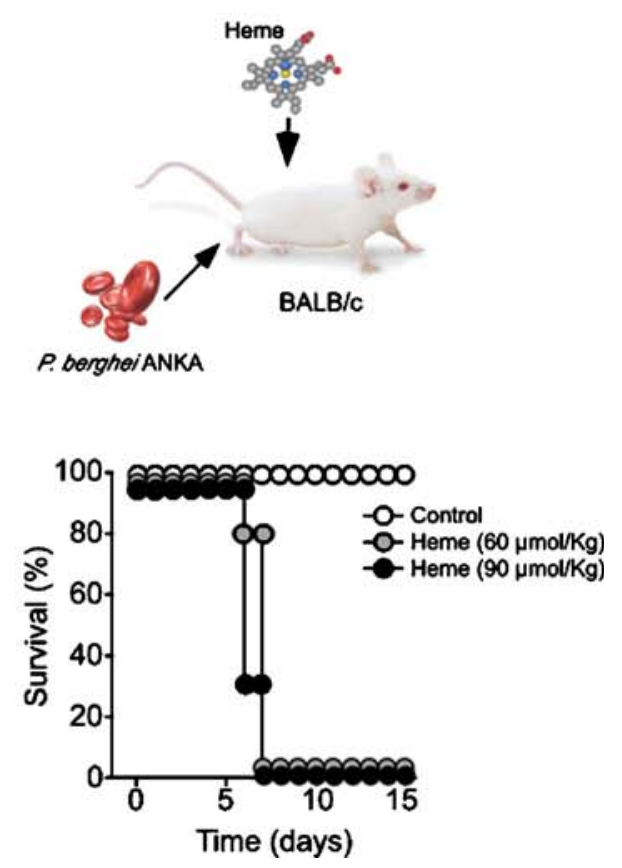


\section{Effector mechanism(s) via which free heme triggers the onset of cerebral malaria}

The mechanism(s) via which free heme precipitates the pathogenesis of severe malaria, and in particular that of cerebral malaria, are not fully elucidated. Cerebral malaria is associated with the development of $\mathrm{BBB}$ disruption and brain edema in both mice [8] and humans [85] (reviewed in [5]). However, the molecular mechanism(s) leading to BBB disruption are not fully understood. Postmortem studies in humans diagnosed with cerebral malaria suggest that BBB leakage is associated with adhesion of infected RBCs to brain microvascular endothelial cells, a phenomenon referred to as $\mathrm{RBC}$ sequestration (reviewed in [3, 4]). A functional link between these two events, i.e., BBB leakage and RBC sequestration, is supported by a series of observations suggesting that adhesion of infected RBCs to endothelial cells in vitro can induce the disruption of tight junctions, a multiprotein structure that maintains BBB integrity (reviewed in [3, 4]). However, there are probably additional mechanisms that can operate, independently of $\mathrm{RBC}$ sequestration, to trigger BBB disruption.

Using an in vitro assay in which brain endothelial cells form tight junctions, free heme was found to promote the disruption tight junction function [8]. This effect requires the presence of ROS, which would explain why free heme triggers BBB disruption only in Plasmodium-infected but not in naïve mice [8]. This observation also suggests that $\mathrm{CO}$ suppresses BBB disruption by preventing the accumulation of free heme in the brain microvasculature [8]. Given the above, we propose that $\mathrm{CO}$ might be used to suppress the onset of cerebral malaria for as long as plasma free heme concentration is kept below a certain threshold level at which $\mathrm{BBB}$ disruption occurs and $\mathrm{CO}$ would lose its protective effect [8]. Whether a similar therapeutic effect would be attained in children diagnosed as having or at risk of developing cerebral malaria remains to be established. Finally, and assuming that free heme is involved in the pathogenesis of severe and/or cerebral malaria in humans, one could consider measuring plasma free heme concentration to diagnose this pathologic condition.

There are several unsolved issues raised by these findings including the identification of the sources of ROS that oxidize cell-free $\mathrm{Hb}$, leading to the generation of free heme and to the onset of cerebral malaria. Based on the observation that $\mathrm{NAD}(\mathrm{P}) \mathrm{H}$ gp $91^{\text {phox }}$-deficient mice can develop cerebral malaria, it has been suggested that ROS are probably not involved in its pathogenesis [86]. Our interpretation is somehow different. We propose that while ROS are most probably involved in the pathogenesis of cerebral malaria, gp91 $1^{\text {phox }}$ is probably not the main source of ROS leading to the onset of this disease. By extending this line of thought, one could consider many other putative sources of superoxide generating systems. These include the gp91 ${ }^{\text {phox }}$ homologue Nox genes, e.g., Nox4 and Nox1, both of which are major components of vascular NAD $(\mathrm{P}) \mathrm{H}$ oxidase-like complexes operating in the brain microvasculature. In addition, the brain vasculature also expresses relatively high levels of xanthine oxidase and cyclooxygenase-1, both of which are potent superoxide anion producers. Another possibility is that the reducing potential of the brain microvasculature might be altered during Plasmodium infection in a way that would promote the accumulation of ROS. This could be a direct consequence of decreased expression of antioxidant genes, e.g., FtH, superoxide dismutase, catalase, or glutathione peroxidase. While the participation of these host genes in the pathogenesis of severe malaria and/or cerebral malaria remains to be tested, it becomes apparent that many possible sources of ROS or their regulators may be involved in its pathogenesis (Fig. 5).

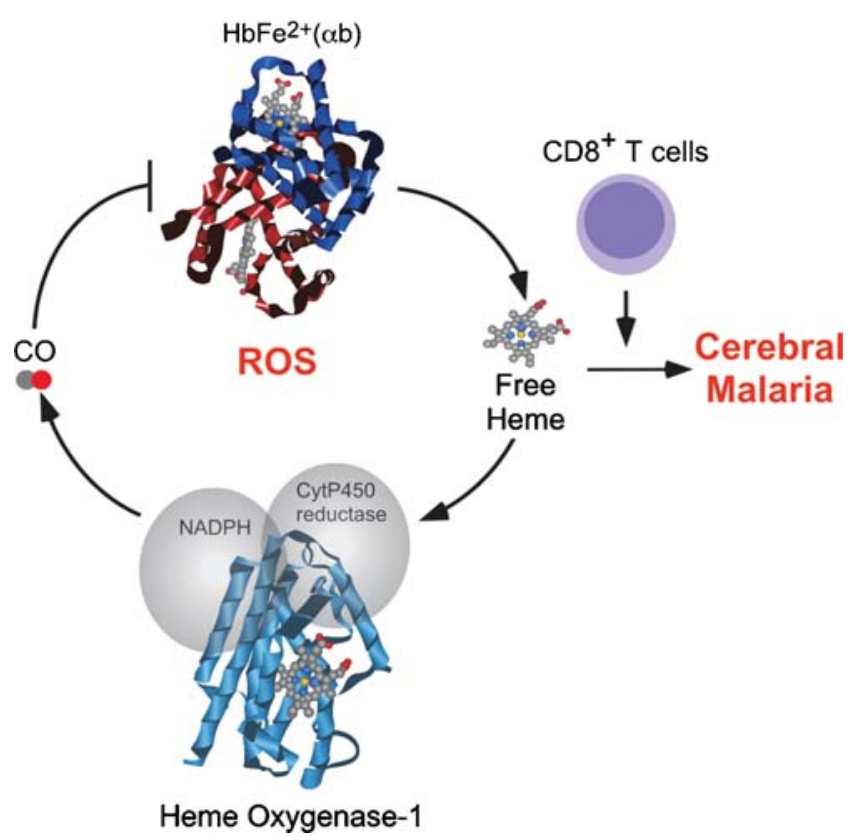

Fig. $5 \mathrm{CO}$ prevents the onset of cerebral malaria via inhibition of heme release from cell-free $\mathrm{Hb}$. When exposed to ROS generated in the brain vasculature by enzymes such as $\mathrm{NAD}(\mathrm{P}) \mathrm{H}$ oxidase, xanthine oxidase, cyclooxygenase, lipoxygenases, and/or riboflavin, dimeric cell-free ferrous $\mathrm{HbFe}^{2+}(\alpha \beta)$ is oxidized into ferric $\mathrm{HbFe}^{3+}(\alpha \beta)$, i.e., metHb (not shown), which releases heme promptly. Accumulation of free heme in plasma of Plasmodium-infected mice allows the $\mathrm{Fe}$ contained within the protoporhyrin IX ring of heme to participate in further generation of ROS via the Fenton chemistry. ROS synergize with activated $\mathrm{CD}^{+} \mathrm{T}$ cells to trigger the development of cerebral malaria. When the expression of HO-1 is induced, free heme availability is reduced via two pathways: (1) heme degradation and (2) generation of $\mathrm{CO}$, which binds dimeric cell-free ferrous $\mathrm{HbFe}^{2+}$ $(\alpha \beta)$ and suppresses further heme release from $\mathrm{Hb}$. The combined effect of HO-1 and its end product $\mathrm{CO}$ suppresses the onset of cerebral malaria in mice [8] 


\section{Integrating the heme/HO-1/CO system with other mechanisms contributing to the pathogenesis of cerebral malaria}

Unfettered expression of pro-inflammatory genes is most probably a central component in the pathogenesis of severe malaria and/or cerebral malaria [87]. Given the above, the anti-inflammatory effects of $\mathrm{CO}$ should contribute to prevent the onset of these pathologic conditions [8, 61] (reviewed in [66]). In support of this notion, CO reduces the expression of key pro-inflammatory genes involved in the pathogenesis of cerebral malaria in mice, e.g., ICAM-1/ CD54, vascular cell adhesion molecule-1 (VCAM-1/ CD106), TNF, LT, and interferon-gamma (IFN- $\gamma$ ) [8].

As discussed under "Deleterious effects of free heme", recognition of Plasmodium-derived PAMP by host PRR might be involved in the pathogenesis of severe malaria in humans [10]. When bound to the heme prosthetic group of the gp91 $1^{\text {phox }}$ subunit of the superoxide anion-generating enzyme $\mathrm{NAD}(\mathrm{P}) \mathrm{H}$ oxidase, $\mathrm{CO}$ inhibits ROS production in Mø [88], thus effect inhibits TLR2, 4, 5, and 9 signaling [88]. It is possible therefore that inhibition of $\mathrm{NAD}(\mathrm{P}) \mathrm{H}$ oxidase by $\mathrm{CO}$ or other gp91 ${ }^{\text {phox }}$-like superoxide-generating enzymes should contribute to prevent the involvement of these PRR in the onset of severe malaria.

While immunocompetent mice require the expression of HO-1 to prevent the onset of cerebral malaria, this is no longer the case when mice lack $\mathrm{T}$ and $\mathrm{B}$ cells, i.e., severe combined immunodeficiency or when $\mathrm{CD}^{+} \mathrm{T}$ cells are depleted from immunocompetent mice [8]. This would suggest that HO-1 down-modulates the activation or effector function of $\mathrm{CD}^{+} \mathrm{T}$ cells and/or that it acts in the brain microvasculature to prevent the cytotoxic effects of $\mathrm{CD}^{+} \mathrm{T}$ cells. The observation that pharmacologic induction of $\mathrm{HO}-1$ or exposure to $\mathrm{CO}$ results in a profound inhibition of $\mathrm{CD}^{+} \mathrm{T}$ cell sequestration in the brain of Plasmodium-infected mice [8] suggests that $\mathrm{CO}$ suppresses $\mathrm{CD}^{+} \mathrm{T}$ cells activation and/or effector function. As free heme can act as a potent $T$ cell mitogen $[89,90]$, it is possible that inhibition of heme release from cell-free $\mathrm{Hb}$ would also down modulate the activation and/or effector function of $\mathrm{CD}^{+} \mathrm{T}$ cells.

There is yet another mechanism via which $\mathrm{CO}$ might exert protective effects that could prevent the pathogenesis of cerebral malaria. Plasmodium infection is associated with a profound reduction of NO bioavailability both in mice [9] and in humans [91], an effect that precipitates the onset of cerebral malaria in mice [9]. Reduction of NO bioavailability occurs via several pathways, including the release of arginase by infected $\mathrm{RBCs}$, an enzyme that degrades the rate-limiting substrate for NO synthesis, i.e., arginine (reviewed in [23]). In addition, cell-free $\mathrm{Hb}$ also acts as a potent NO scavenger, an effect that reduces NO bioavailability $[9,92]$. It has been recently shown that in a similar way to $\mathrm{CO}$, $\mathrm{NO}$ inhalation or administration of pharmacologic compounds that release NO suppresses the onset of severe malaria in mice [9]. As NO and CO target the same heme prosthetic groups in cell-free $\mathrm{Hb}$, it is possible that these two gases may interact functionally. For example, it is conceivable that once bound to cell-free $\mathrm{Hb}$, $\mathrm{CO}$ could reduce its NO scavenging capacity, thus increasing NO bioavailability and suppressing in this manner the onset of cerebral malaria [9]. This might occur even if $\mathrm{CO}$ binds to the heme groups of cell-free $\mathrm{Hb}$ with an affinity that is $\sim 1,500$ lower to that of NO, as contrary to $\mathrm{CO}$, NO is very labile, reacting avidly with ROS to generate peroxynitrite. This hypothesis is currently being tested in our laboratory.

\section{Concluding remarks}

The data we have obtained in rodent models of malaria suggest that survival of a Plasmodium-infected host is strictly dependent on its ability to induce the expression of the heme-catalyzing enzyme $\mathrm{HO}-1 . \mathrm{CO}$, an end product of heme catabolism by HO-1, supresses the development of severe malaria, i.e., cerebral malaria. The protective effect of $\mathrm{CO}$ is mediated not only via its cytoprotective and anti-inflammatory effects but also via inhibition of heme release from cell-free $\mathrm{Hb}$ generated during the blood stage of Plasmodium infection. One of the key notions that arise from these findings is that at least in mice, free heme seems to play a critical role in the pathogenesis of cerebral malaria. If this also proves to be the case in humans, then one might be able to use plasma free heme concentration to diagnose the onset of severe and/or cerebral malaria and eventually use therapeutic approaches that target free heme, including $\mathrm{CO}$ administration, to overcome the onset of these pathologic conditions.

Acknowledgments We thank Marcelo Bozza (Universidade Federal do Rio de Janeiro, Brasil) and Fritz H. Bach (Harvard Medical School) for critically reviewing this manuscript, Sofia Rebelo and Sílvia Cardoso (Instituto Gulbenkian de Ciência) for mouse breeding and genotyping and all other members of the inflammation laboratory (Instituto Gulbenkian de Ciência) for critical input. This work was partially supported by "Fundação para a Ciência e Tecnologia", Portugal grants POCTI/SAU-MNO/56066/2004 and PTDC/SAU-MII/ 65765/2006 to MPS, PTDC/SAU-MII/71140/2006 and SFRH/BPD/ $21707 / 2005$ to AF. Support was also provided by grants from Gemi Fund (Linde Healthcare) to MPS and OTKA-61546, ETT-337/06, RET-06/2004 and MTA-DE-11003 to JB.

Open Access This article is distributed under the terms of the Creative Commons Attribution Noncommercial License which permits any noncommercial use, distribution, and reproduction in any medium, provided the original author(s) and source are credited. 


\section{References}

1. WHO (2000) Expert Committee on Malaria: 20th Report. http:// www.rbm.who.int/docs/ecr20.pdf

2. Prudencio M, Rodriguez A, Mota MM (2006) The silent path to thousands of merozoites: the Plasmodium liver stage. Nat Rev Microbiol 4:849-856

3. Schofield L, Grau GE (2005) Immunological processes in malaria pathogenesis. Nat Rev Immunol 5:722-735

4. Haldar K, Murphy SC, Milner DA, Taylor TE (2007) Malaria: mechanisms of erythrocytic infection and pathological correlates of severe disease. Annu Rev Pathol 2:217-249

5. Idro R, Jenkins NE, Newton CR (2005) Pathogenesis, clinical features, and neurological outcome of cerebral malaria. Lancet Neurol 4:827-840

6. Miller LH, Baruch DI, Marsh K, Doumbo OK (2002) The pathogenic basis of malaria. Nature 415:673-679

7. Marsh K, Forster D, Waruiru C et al (1995) Indicators of lifethreatening malaria in African children. $\mathrm{N}$ Engl J Med 332: 1399-1404

8. Pamplona A, Ferreira A, Balla J et al (2007) Heme oxygenase-1 and carbon monoxide suppress the pathogenesis of experimental cerebral malaria. Nat Med 13:703-710

9. Gramaglia I, Sobolewski P, Meays D et al (2006) Low nitric oxide bioavailability contributes to the genesis of experimental cerebral malaria. Nat Med 12:1417-1422

10. Gazzinelli RT, Denkers EY (2006) Protozoan encounters with Toll-like receptor signalling pathways: implications for host parasitism. Nat Rev Immunol 6:895-906

11. Krishnegowda G, Hajjar AM, Zhu J et al (2005) Induction of proinflammatory responses in macrophages by the glycosylphosphatidylinositols of Plasmodium falciparum: cell signaling receptors, glycosylphosphatidylinositol (GPI) structural requirement, and regulation of GPI activity. J Biol Chem 280:86068616

12. Parroche P, Lauw FN, Goutagny N et al (2007) Malaria hemozoin is immunologically inert but radically enhances innate responses by presenting malaria DNA to Toll-like receptor 9. Proc Natl Acad Sci U S A 104:1919-1924

13. Coban C, Ishii KJ, Uematsu S et al (2007) Pathological role of Toll-like receptor signaling in cerebral malaria. Int Immunol 19:67-79

14. Mockenhaupt FP, Cramer JP, Hamann L et al (2006) Toll-like receptor (TLR) polymorphisms in African children: common TLR-4 variants predispose to severe malaria. Proc Natl Acad Sci U S A 103:177-182

15. Mockenhaupt FP, Hamann L, von Gaertner C et al (2006) Common polymorphisms of toll-like receptors 4 and 9 are associated with the clinical manifestation of malaria during pregnancy. J Infect Dis 194:184-188

16. Khor CC, Chapman SJ, Vannberg FO et al (2007) A Mal functional variant is associated with protection against invasive pneumococcal disease, bacteremia, malaria and tuberculosis. Nat Genet 39:523-528

17. Togbe D, Schofield L, Grau GE et al (2007) Murine cerebral malaria development is independent of toll-like receptor signaling. Am J Pathol 170:1640-1648

18. Lepenies B, Cramer JP, Burchard GD, Wagner H, Kirschning CJ, Jacobs T (2008) Induction of experimental cerebral malaria is independent of TLR2/4/9. Med Microbiol Immunol 197:3944

19. Good MF, Xu H, Wykes M, Engwerda CR (2005) Development and regulation of cell-mediated immune responses to the blood stages of malaria: implications for vaccine research. Annu Rev Immunol 23:69-99
20. Raberg L, Sim D, Read AF (2007) Disentangling genetic variation for resistance and tolerance to infectious diseases in animals. Science 318:812-814

21. Francis SE, Sullivan DJ Jr, Goldberg DE (1997) Hemoglobin metabolism in the malaria parasite Plasmodium falciparum. Annu Rev Microbiol 51:97-123

22. Orjih AU, Banyal HS, Chevli R, Fitch CD (1981) Hemin lyses malaria parasites. Science 214:667-669

23. Rother RP, Bell L, Hillmen P, Gladwin MT (2005) The clinical sequelae of intravascular hemolysis and extracellular plasma hemoglobin: a novel mechanism of human disease. JAMA 293:1653-1662

24. Jeney V, Balla J, Yachie A et al (2002) Pro-oxidant and cytotoxic effects of circulating heme. Blood 100:879-887

25. Balla J, Balla G, Jeney V, Kakuk G, Jacob HS, Vercellotti GM (2000) Ferriporphyrins and endothelium: a 2-edged swordpromotion of oxidation and induction of cytoprotectants. Blood 95:3442-3450

26. Balla J, Jacob HS, Balla G, Nath K, Eaton JW, Vercellotti GM (1993) Endothelial-cell heme uptake from heme proteins: induction of sensitization and desensitization to oxidant damage. Proc Natl Acad Sci U S A 90:9285-9289

27. Balla J, Vercellotti GM, Jeney V et al (2005) Heme, heme oxygenase and ferritin in vascular endothelial cell injury. Mol Nutr Food Res 49:1030-1043

28. Tenhunen R, Marver HS, Schmid R (1968) The enzymatic conversion of heme to bilirubin by microsomal heme oxygenase. Proc Natl Acad Sci U S A 61:748-755

29. Seong S-Y, Matzinger P (2004) Hydrophobicity: an ancient damage-associated molecular pattern that initiates innate immune responses. Nat Rev Immunol 4:469-478

30. Figueiredo RT, Fernandez PL, Mourao-Sa DS et al (2007) Characterization of heme as activator of Toll-like receptor 4. J Biol Chem 282:20221-20229

31. Porto BN, Alves LS, Fernandez PL et al (2007) Heme induces neutrophil migration and reactive oxygen species generation through signaling pathways characteristic of chemotactic receptors. J Biol Chem 282:24430-24436

32. Graca-Souza AV, Arruda MA, de Freitas MS, Barja-Fidalgo C, Oliveira PL (2002) Neutrophil activation by heme: implications for inflammatory processes. Blood 99:4160-4165

33. Arruda MA, Rossi AG, de Freitas MS, Barja-Fidalgo C, GracaSouza AV (2004) Heme inhibits human neutrophil apoptosis: involvement of phosphoinositide 3-kinase, MAPK, and NFkappaB. J Immunol 173:2023-2030

34. Grau GE, Fajardo LF, Piguet PF, Allet B, Lambert PH, Vassalli P (1987) Tumor necrosis factor (cachectin) as an essential mediator in murine cerebral malaria. Science 237:1210-1212

35. Slater AF, Cerami A (1992) Inhibition by chloroquine of a novel haem polymerase enzyme activity in malaria trophozoites. Nature 355:167-169

36. Jiang N, Tan NS, Ho B, Ding JL (2007) Respiratory proteingenerated reactive oxygen species as an antimicrobial strategy. Nat Immunol 8:1114-1122

37. Kristiansen M, Graversen JH, Jacobsen C et al (2001) Identification of the haemoglobin scavenger receptor. Nature 409:198-201

38. Maeda N, Yang F, Barnett DR, Bowman BH, Smithies O (1984) Duplication within the haptoglobin $\mathrm{Hp} 2$ gene. Nature 309: 131-135

39. Atkinson SH, Mwangi TW, Uyoga SM et al (2007) The haptoglobin 2-2 genotype is associated with a reduced incidence of Plasmodium falciparum malaria in children on the coast of Kenya. Clin Infect Dis 44:802-809

40. Trape JF, Fribourg-Blanc A, Bosseno MF, Lallemant M, Engler R, Mouchet J (1985) Malaria, cause of ahaptoglobinaemia in Africans. Trans R Soc Trop Med Hyg 79:430-434 
41. Uko EK, Udoh AE, Etukudoh MH (2003) Methaemoglobin profile in malaria infected children in Calabar. Niger $\mathrm{J}$ Med 12:94-97

42. Anstey NM, Hassanali MY, Mlalasi J, Manyenga D, Mwaikambo ED (1996) Elevated levels of methaemoglobin in Tanzanian children with severe and uncomplicated malaria. Trans $\mathrm{R}$ Soc Trop Med Hyg 90:147-151

43. Hvidberg V, Maniecki MB, Jacobsen C, Hojrup P, Moller HJ, Moestrup SK (2005) Identification of the receptor scavenging hemopexin-heme complexes. Blood 106:2572-2579

44. Stocker R, Yamamoto Y, McDonagh AF, Glazer AN, Ames BN (1987) Bilirubin is an antioxidant of possible physiological importance. Science 235:1043-1046

45. Maines MD (2005) New insights into biliverdin reductase functions: linking heme metabolism to cell signaling. Physiology (Bethesda) 20:382-389

46. Balla G, Jacob HS, Balla J et al (1992) Ferritin: a cytoprotective antioxidant strategem of endothelium. J Biol Chem 267:1814818153

47. Cozzi A, Corsi B, Levi S, Santambrogio P, Albertini A, Arosio P (2000) Overexpression of wild type and mutated human ferritin $\mathrm{H}$-chain in HeLa cells - in vivo role of ferritin ferroxidase activity. J Biol Chem 275:25122-25129

48. Berberat PO, Katori M, Kaczmarek E et al (2003) Heavy chain ferritin acts as an antiapoptotic gene that protects livers from ischemia reperfusion injury. FASEB J 17:1724-1726

49. Harrison PM, Arosio P (1996) Ferritins-molecular properties, iron storage function and cellular regulation. Biochimica et Biophysica Acta-Bioenergetics 1275:161-203

50. Pham CG, Bubici C, Zazzeroni F et al (2004) Ferritin heavy chain upregulation by NF-kappaB inhibits TNFalpha-induced apoptosis by suppressing reactive oxygen species. Cell 119:529-542

51. Otterbein LE, Soares MP, Yamashita K, Bach FH (2003) Heme oxygenase-1: unleashing the protective properties of heme. Trends Immunol 24:449-455

52. Schluesener HJ, Kremsner PG, Meyermann R (2001) Heme oxygenase-1 in lesions of human cerebral malaria. Acta Neuropathol (Berl) 101:65-68

53. Medana IM, Mai NT, Day NP et al (2001) Cellular stress and injury responses in the brains of adult Vietnamese patients with fatal Plasmodium falciparum malaria. Neuropathol Appl Neurobiol 27:421-433

54. Clark IA, Awburn MM, Harper CG, Liomba NG, Molyneux ME (2003) Induction of HO-1 in tissue macrophages and monocytes in fatal falciparum malaria and sepsis. Malar J 2:41

55. Jison ML, Munson PJ, Barb JJ et al (2004) Blood mononuclear cell gene expression profiles characterize the oxidant, hemolytic, and inflammatory stress of sickle cell disease. Blood 104:270 280

56. Yachie A, Niida Y, Wada T et al (1999) Oxidative stress causes enhanced endothelial cell injury in human heme oxygenase-1 deficiency. J Clin Invest 103:129-135

57. Exner M, Minar E, Wagner O, Schillinger M (2004) The role of heme oxygenase-1 promoter polymorphisms in human disease. Free Radic Biol Med 37:1097-1104

58. Takeda M, Kikuchi M, Ubalee R et al (2005) Microsatellite polymorphism in the heme oxygenase- 1 gene promoter is associated with susceptibility to cerebral malaria in Myanmar. Jpn J Infect Dis 58:268-271

59. Epiphanio S, Mikolajczak SA, Goncalves et al (2008) Heme oxygenase- 1 is an anti-inflammatory host factor that promotes murine plasmodium liver infection. Cell Host Microbe 3, 331-338

60. Sato K, Balla J, Otterbein L et al (2001) Carbon monoxide generated by heme oxygenase-1 suppresses the rejection of mouse to rat cardiac transplants. J Immunol 166:4185-4194
61. Otterbein LE, Bach FH, Alam J et al (2000) Carbon monoxide mediates anti-inflammatory effects via the mitogen activated protein kinase pathway. Nat Med 6:422-428

62. Otterbein LE, Zuckerbraun BS, Haga M et al (2003) Carbon monoxide suppresses arteriosclerotic lesions associated with chronic graft rejection and with balloon injury. Nat Med 9:183-190

63. Chora AA, Fontoura P, Cunha A et al (2007) Heme oxygenase-1 and carbon monoxide suppress autoimmune neuroinflammation. J Clin Invest 117:438-447

64. Ollinger R, Bilban M, Erat A et al (2005) Bilirubin: a natural inhibitor of vascular smooth muscle cell proliferation. Circulation 112:1030-1039

65. Brouard S, Otterbein LE, Anrather J et al (2000) Carbon monoxide generated by heme oxygenase 1 suppresses endothelial cell apoptosis. J Exp Med 192:1015-1026

66. Bilban M, Haschemi A, Wegiel B, Chin BY, Wagner O, Otterbein LE (2008) Heme oxygenase and carbon monoxide initiate homeostatic signaling. J Mol Med 86:267-279

67. Stone JR, Sands RH, Dunham WR, Marletta MA (1996) Spectral and ligand-binding properties of an unusual hemoprotein, the ferric form of soluble guanylate cyclase. Biochemistry 35:32583262

68. Perutz MF (1990) Mechanisms regulating the reactions of human hemoglobin with oxygen and carbon monoxide. Annu Rev Physiol 52:1-25

69. Kharitonov VG, Sharma VS, Pilz RB, Magde D, Koesling D (1995) Basis of guanylate cyclase activation by carbon monoxide. Proc Natl Acad Sci U S A 92:2568-2571

70. Sharma VS, Magde D (1999) Activation of soluble guanylate cyclase by carbon monoxide and nitric oxide: a mechanistic model. Methods 19:494-505

71. Kim HP, Ryter SW, Choi AM (2005) CO as a cellular signaling molecule. Annu Rev Pharmacol Toxicol 46:411-449

72. Gibson QH, Palmer G, Wharton DC (1965) The binding of carbon monoxide by cytochrome $\mathrm{c}$ oxidase and the ratio of the cytochromes a and A3. J Biol Chem 240:915-920

73. Moncada S, Erusalimsky JD (2002) Does nitric oxide modulate mitochondrial energy generation and apoptosis? Nat Rev Mol Cell Biol 3:214-220

74. Zuckerbraun BS, Chin BY, Bilban M et al (2007) Carbon monoxide signals via inhibition of cytochrome $c$ oxidase and generation of mitochondrial reactive oxygen species. FASEB J 21:1099-1106

75. Bilban M, Bach FH, Otterbein SL et al (2006) Carbon monoxide orchestrates a protective response through PPARgamma. Immunity 24:601-610

76. Chin BY, Jiang G, Wegiel B et al (2007) Hypoxia-inducible factor 1 alpha stabilization by carbon monoxide results in cytoprotective preconditioning. Proc Natl Acad Sci U S A 104: 5109-5114

77. Ono K, Han J (2000) The p38 signal transduction pathway: activation and function. Cell Signal 12:1-13

78. Silva G, Cunha A, Gregoire IP, Seldon MP, Soares MP (2006) The antiapoptotic effect of heme oxygenase-1 in endothelial cells involves the degradation of p38\{alpha\} MAPK isoform. J Immunol 177:1894-1903

79. Kim HP, Wang X, Zhang J et al (2005) Heat shock protein-70 mediates the cytoprotective effect of carbon monoxide: involvement of p38 beta MAPK and heat shock factor-1. J Immunol 175:2622-2629

80. Kim HP, Wang X, Nakao A et al (2005) Caveolin-1 expression by means of $\mathrm{p} 38$ beta mitogen-activated protein kinase mediates the antiproliferative effect of carbon monoxide. Proc Natl Acad Sci U S A 102:11319-11324

81. Welch JS, Ricote M, Akiyama TE, Gonzalez FJ, Glass CK (2003) PPARgamma and PPARdelta negatively regulate specific subsets 
of lipopolysaccharide and IFN-gamma target genes in macrophages. Proc Natl Acad Sci U S A 100:6712-6717

82. Dioum EM, Rutter J, Tuckerman JR, Gonzalez G, GillesGonzalez MA, McKnight SL (2002) NPAS2: a gas-responsive transcription factor. Science 298:2385-2387

83. Hawking F, Worms MJ, Gammage K (1968) Host temperature and control of 24-hour and 48-hour cycles in malaria parasites. Lancet 1:506-509

84. Cunnington AJ, Kendrick SF, Wamola B, Lowe B, Newton CR (2004) Carboxyhemoglobin levels in Kenyan children with Plasmodium falciparum malaria. Am J Trop Med Hyg 71:4347

85. Brown HC, Chau TT, Mai NT et al (2000) Blood-brain barrier function in cerebral malaria and CNS infections in Vietnam. Neurology 55:104-111

86. Potter SM, Mitchell AJ, Cowden WB et al (2005) Phagocytederived reactive oxygen species do not influence the progression of murine blood-stage malaria infections. Infect Immun 73:49414947

87. Clark IA, Rockett KA (1994) The cytokine theory of human cerebral malaria. Parasitol Today 10:410-412

88. Nakahira K, Kim HP, Geng XH et al (2006) Carbon monoxide differentially inhibits TLR signaling pathways by regulating ROSinduced trafficking of TLRs to lipid rafts. J Exp Med 203:2377-2389

89. Stenzel KH, Rubin AL, Novogrodsky A (1981) Mitogenic and comitogenic properties of hemin. J Immunol 127:2469-2473
90. Novogrodsky A, Suthanthiran M, Stenzel KH (1989) Immune stimulatory properties of metalloporphyrins. J Immunol 143:3981-3987

91. Yeo TW, Lampah DA, Gitawati R et al (2007) Impaired nitric oxide bioavailability and L-arginine reversible endothelial dysfunction in adults with falciparum malaria. J Exp Med 204:2693-2704

92. Reiter CD, Wang X, Tanus-Santos JE et al (2002) Cell-free hemoglobin limits nitric oxide bioavailability in sickle-cell disease. Nat Med 8:1383-1389

93. Maples KR, Kennedy CH, Jordan SJ, Mason RP (1990) In vivo thiyl free radical formation from hemoglobin following administration of hydroperoxides. Arch Biochem Biophys 277:402-409

94. McCormick DJ, Atassi MZ (1990) Hemoglobin binding with haptoglobin: delineation of the haptoglobin binding site on the alpha-chain of human hemoglobin. J Protein Chem 9:735-742

95. Bunn HF, Jandl JH (1968) Exchange of heme among hemoglobins and between hemoglobin and albumin. J Biol Chem 243:465-475

96. Paoli M, Anderson BF, Baker HM, Morgan WT, Smith A, Baker EN (1999) Crystal structure of hemopexin reveals a novel high-affinity heme site formed between two beta-propeller domains. Nat Struct Biol 6:926-931

97. Little HN, Neilands JB (1960) Binding of haematin by human serum albumin. Nature 188:913-915

98. Fasano M, Fanali G, Leboffe L, Ascenzi P (2007) Heme binding to albuminoid proteins is the result of recent evolution. IUBMB Life 59:436-440 